\title{
Promotion Anxieties: jazz promoters within the UK scene
}

Abstract:

Definitions and roles of the promoter within the ecology of the music industries have over recent years become the subject of attention by academics working within the field of popular music studies. It has become accepted that precise definitions are difficult to apply, due to both the varied understanding of the term 'promoter', and the diverse nature of their activities. Where the promoter is the conduit between artist and audience, the ways and means by which this is manifested varies greatly between individuals, and the professional and personal circumstances in which they operate. Rather than further attempting to provide distinct definitions as applied to the promoter, this paper aims to offer a nuanced examination of the motivations, professional networks, and occupational challenges that contribute to the self-perceptions of five promoters working in the context of a local jazz scene within an undisclosed city in the United Kingdom.

INTRODUCTION: 
There is a growing body of academic and industry-commissioned literature concerning the ecology of the live music sector in the United Kingdom. Frith (2007), Riley and Laing $(2005,2008)$ Frith, Brennan, Cloonan and Webster (2010), Burland and Pitts (2010), Brennan and Webster (2011), Wall and Barber (2015) and others have, over the past decade, given attention to the delineation and inner-workings of the music industries and, in the process, identified the roles of the intermediaries that enable artists and audiences to interact in the live performance sphere, including that of the promoter. However, this is a term that is somewhat nebulous, can have different meanings depending on the context in which it is used (and by whom), and can be used to represent a range of people who perform a number of different, and often unrelated tasks. As Brennan and Webster (2011: 2) identify: "a promoter's role is simple to define but complicated to describe". With this in mind, our aim is to not to try to further 'define' the role of producer, but rather to investigate the roles and actions of promoters at a local level in a jazz scene in a UK city. 
In the music industries ecology which includes, but is by no means limited to, artists, managers, agents, music press, record labels and record producers (Frith 2010: 3), the promoter acts as intermediary in the process of cultural production, placing the artist in front of a live audience. In this role, the promoter ascribes a value to individual artists or bands based on combinations of known or projected financial and cultural 'worth', in matching anticipated demand with ticket pricing and venue audience capacities. Within this commercial arena, the artist variously represents a quick return on a promoter's financial risk, or an investment to be nurtured over time. It is common practice, for example in music festival programming, to include high-grossing big names to serve as 'loss leaders' for lesser known or 'fledgling' acts. Conversely, it is not unusual for a promoter to champion an emerging act before it has become commercially viable, with the tacit understanding of future promoter/artist loyalties as and when the relationship becomes profitable.

The promoter is typically cast as 'middle-man' by those whose interactions they enable; a mediator often viewed with mistrust by musicians 
competing for attention (EKOS 2014: 23), and remaining largely

anonymous to the majority of concertgoers. The promoter thereby

occupies a space between the competing, and often conflicting, desires

and expectations of artists and audiences, within the complex economic

and social structures of the cultural industries. Frith (2012: 517) states that

the successful realisation of the promoter's role may be measured through

"organizing musical events that enable audiences to listen to music in an

appropriate way". Such 'appropriateness' is achieved through the measured

consideration of venue size, location and type, and ticket pricing, with the

objective of generating a positive audience experience from that which is

promoted. Running in tandem with Frith's audience-focused perspective is the promoter's stewardship and gatekeeping of the local music scene. It is in this capacity that the promoter adopts decision-making roles that impact directly on who is booked to play, how often, and for what fee. This level of control can even extend to the promoter acting as producer and fixer in assembling personnel lineups for specific musical projects, be it a local pick-up band for a visiting artist, a band or orchestra to play specific 
repertoire, or in the bringing together of specific artists - any of which can arguably have a palpable effect on the performance artefact.

As is the case for musicians, other agents within the live music sector, including venue owners, front-of-house staff, sound and lighting engineers, and ticketing agencies, are all co-dependent on the activities of the promoter (Brennan and Webster 2011). Promoters may therefore also be viewed as the "lifeblood" (Lawes et al. 2016: 35) without which the health and functionality of the live music sector would be significantly compromised. In an environment where many musicians have come to accept live performance and related merchandising of recorded work as the primary income generator in the straitened age of digital streaming and free downloads (Frith 2007; Montoro-Pons \& Cuadrado-García 2010), the promoter's role as the sector's gatekeeper has become increasingly focal to the financial, aesthetic and social underpinning of individual scenes. This responsibility is not always easily managed nor, for that matter, handsomely remunerated. Where in recent times the press has made much 
of artists' increased financial reliance on, and returns from, the live sector, such claims typically refer to established, mainstream acts on international and festival touring circuits. As such, they do not apply readily to the majority of jazz musicians for whom, with the exception of the very few, opportunities to present their music and develop a fan-base, or even to make a living wage, are typically more elusive. The difficulties involved in squaring the financial circle for jazz musicians have, unsurprisingly, direct impact on the earning potential of those who promote their music. Many promoters work for free or relatively modest remuneration. Some do so with the fiscal safety net of public or corporate funding, and others through promoting jazz as part of a bigger offering, in which more significant financial returns are achieved through presenting more universally popular genres of music to subsidise their jazz programming. For others, commercial viability plays little part in their promotional objectives, their motivation being closer to that of an 'activist' within the subculture of jazz. 
The promotion of jazz in the UK takes place across a broad spectrum of performance spaces (Lawes et al. 2016: 35), influencing and responding to the zeitgeist of public taste and cultural appetite. Venues playing host to live jazz performances are observed in live music censuses such as 'The Value of Jazz in Britain II' (Riley and Laing 2010) and 'Music Sector Review' (EKOS 2014) for example, as ranging in capacity and status from the civic concert hall to the back room of a pub, the dedicated music venue to the private sitting room. Over its century-long evolution, the performance and reception of jazz has become entrenched in formality and ritual (Pinheiro, 2014). Manifestations and expectations of these normative constructs vary, not only dependent on the stylistic variety of jazz being presented, but also on the nature of the space in which it is being performed, and the audience demographic sought. At one end of this spectrum of expectation is the 'listening gig' - one in which performer and audience are formally separated, each with clear active and passive functions, respectively. At the other is the 'participatory gig' - in which there is a less marked divide between 'performers' and 'audience', with the latter engaging in a more 
socially active role, whether by contributing to the musical content (as in the case of jam-sessions), by dancing, by calling for specific requests or by applauding and vocally acknowledging individual soloists. Returning to Frith's idea of 'appropriateness', it is the promoter's responsibility to fulfil or, in some cases, creatively confound these expectations (Lawes et al. 2016: 10) by demonstrating an understanding of performance norms.

Central to the social construction of the jazz scene is the live interaction between musician and audience (Burland and Pitts 2012). The degree of intimacy in this interaction is arguably unique in the presentation of jazz. The majority of UK jazz venues are small, attracting audiences of less than 100 (Riley and Laing 2010). This setting affords the audience proximity with participation, including verbal affirmation and the applauding of featured solos, both expected and encouraged. Performers' inclusion of musical references to the music's recorded history, whether by way of stylistic mimicry or literal musical 'quotes', encourage a sense of shared listening experiences between musician and listener, and a codified means of membership to the scene. Verbal communication, on stage and off, is 
similarly infused with terms borrowed from a different era steeped in the constructed narrative of jazz (McRae 2001; Leonard 1986), a 'secret' language that serves to identify the fellow jazz fan.

The comforts of incorporation into the jazz scene, however, belie frictions amongst its subscribers. Jazz as a genre has over its century-long development given rise to a canon of rich stylistic variety and a diversity of philosophical underpinnings. Jazz fans typically profess an affinity with one or more historically located stylistic variants leading to abundant, scenewide discourse concerning delineation and authenticity. Within such a complex discourse one might, for the sake of convenience, present a binary observation that jazz fans can be typified as those committed to the preservation of some or more aspects of the music's cultural heritage, and those of a less prescriptive, culturally inclusive outlook. Where understandings of histories might be shared to a degree, the future of jazz (how it is played, where, and to whom) is a subject of consistent contention amongst its fans. Younger jazz musicians increasingly look to their counterparts in the field of popular music for inspiration, whether 
through the integration of emerging technologies, web-based audience development and communication tools, or through less traditionally defined live presentation of their music. In the promotion of jazz, the fault lines between tradition and innovation within the broadly defined jazz scene are difficult to navigate, and the needs and desires of both hard to satisfy. Jazz continues to lag in relation to the more 'web 2.0-versed' popular music industries (Medbøe and Dias 2014) in the promotion of its musical culture to prospective audiences. In this period of self-examination and outward-looking re-invention, the live promoter's roles, and understandings of the scene that they operate within, are critical to the continued survival of jazz as it embarks on its second century of evolution. Jazz can therefore, on one hand, be seen as a culturally transformative art form and, on the other, one that is tradition based - or, indeed, combinations thereof. Proponents of both ideological standpoints are to a large extent dependent on those who steward it through change or, indeed, safeguard of its heritage. Promoters therefore significantly define the live scenes in which they present. Understanding their motivations 
helps to make sense not only of current and historical circumstances in the staging of live jazz, but also provides a starting point for coming generations of jazz promoters. This article seeks to probe these issues and contribute to knowledge in this area by reporting on a qualitative study that explores the motivations, self-identities, areas of activity, and economic pressures affecting our participants of five active jazz promoters in an undisclosed city within the United Kingdom. ${ }^{1}$ Participant interviews include discussion of the tensions between the economic sustainability of their activities, fiscal accountability, regulatory governance (Brennan and Webster 2011: 15 - 17), the state of the industry, stewardship of the local talent pool, cultural gate-keeping, and responding to audience demand.

\section{METHOD:}

Five promoters were invited to take part in this research. This purposive homogeneous sampling was deemed appropriate by the authors as our focus on a specific group demanded that we speak to specific individuals working in this area. The areas of activity in which the promoters are

\footnotetext{
${ }^{1}$ The city is undisclosed in order to preserve the anonymity of the particiants.
} 
primarily engaged are: the programming of a city-wide international jazz festival [Promoter A]; Individual jazz concerts within a wider, non-jazz offering [Promoter B]; A dedicated jazz venue [Promoter C]; A weekly jazz night and jam-session: [Promoter D]; Ad-hoc performances of marginal music (i.e. outside of the mainstream jazz offering, such as free improvisation) [Promoter E].

Individual semi-structured interviews were conducted, and each was recorded (with the consent of the interviewee) and fully transcribed. Interview topics pertained to the roles and responsibilities of the promoter, the nature of the scene they operate in and their perceived position within it, financial issues (including funding, revenue streams, and commercial pressures), and cultural/artistic pressures. Each author conducted an individual thematic analysis, analyzing the data for emergent themes. These were distilled into a single list of themes to ensure a consistent interpretation of the data. 
All names and locations/venues have been anonymised in order to

preserve the anonymity of the interviewees.

\section{FINDINGS:}

\section{Motivation and Impetus}

In our attempt to understand the ecology of jazz promotion in the UK city in which this research took place, we were keen to probe interviewees about their motivations for working in this field. Although the individual circumstances of the promoters differ, a number of commonalities were observed. When reflecting on why they were drawn to promote jazz, three of the interviewees reported that they did so, at least in part, because they identified themselves as musicians (whether of professional or amateur standing) who wanted to be involved in the creation and organisation of gigs.

Promoter C: / started [promoting] because / am a musician, so I've always played and I've always wanted to create gigs. 
Promoter D: I play piano. Not well, but I am enthusiastic at home with the headphones on basically, that's about the best way to describe it.

Promoter E: To work, to actually play myself ...

Whether as a means of taking charge of their own musical aspirations (Wall T \& Barber S 2015: 125) or simply in order to create opportunities for fellow musicians, there was a clear relationship between playing an instrument and perceiving themselves as musicians, and promoting gigs. However, other factors beyond a wish to perform and be involved musically, such as a drive or sense of responsibility to make things happen, played an equally important part in interviewees' motivations to promote:

Promoter C: I've always been an organizer which is unlike a lot of musicians who sort of wait for the phone to ring. I am more proactive, so I go out there and get gigs for myself and then thinking, if / can do that, I can get gigs for others and do some things.

Promoter D: I was unaware of what went on in the [local] jazz scene until, six, seven years ago ... I just thought: "I listen to these masters and 
it can't be as good as that" and I was ignorant of the quality of jazz that was taking place that was home-grown ... [...] My personal motivation for promoting at [a named venue] had everything to do with serving people of a certain age like me who just didn't know what was going on out there, and bringing them in.

The personal circumstances of individual promoters interviewed had clear baring on philosophy and impetus. Operating at the less commercially rewarding end of the spectrum, one respondent clearly valued process over material gain:

Promoter E: ... we're egocentric, we need an audience and also sometimes you play really well with that stimulus, also we have a social duty, you know, we're musicians, why do we exist but to inspire people and give them a good time? To go out and play is like a wonderfully virtuous circle where a musician gains from it, the audience gains from it and we all starve together [laughs]. 
Similarly, the promoters' passion for the music as a motivating force for their activities also came to the fore:

Promoter A1: I think the natural way for most jazz promoters, including myself, is that you're a jazz fan, and you think to yourself "how can I promote this music so I can hear more of it myself?" [...] And, why do I promote it now? Because, I think that jazz is an extraordinarily fulfilling music for people to listen to, to engage with.

One promoter whose incentive to promote jazz was not related to personal musical practice, or indeed any exclusive passion for jazz, took a more universal, if equally zealous, perspective in describing the bringing together of performers and audience under one roof - albeit with the caveat of doing so for financial gain.

Promoter B: My motivation, the thing that gives me quite a buzz about it, is when a show goes well, it sells well, the artist is happy, the audience ... you know there is a busy room or it's sold-out, the audience get this great feedback and it starts bouncing back and forward 
between the artist and the audience and you get this kind of euphoric experience... you know, the artist enjoying it, the audience enjoying it and you are witness to it and facilitated it - and without your input that experience for all these people wouldn't have happened... so that's one of the rewards.../ get paid.

The idea of promoter as a key figure in the creation of cultural and social capital emerged. The majority of interviewees seemed to consider themselves as standard-bearers for jazz, and some saw their role as contributing to audience education, for example by providing context to programming in mail-outs and on social media:

Promoter C: I see [education] as an important function, definitely yeah, I try and work in some kind of story or angle or snippet or news snippet or YouTube clip or something that kind of interesting that will catch people's eyes or ears [in the promoter's use of promotional social media]. 
One promoter found the term 'educator' too self-aggrandizing,

interpreting their role more as a champion of the music, through creating opportunities for the discovery of live jazz on a local level driven by a sense of moral obligation. Promoter $D$ felt that their role was more akin to being:

Sort of 'herder of the ignorant', maybe? [...] An evangelist, rather than educator. I'm not teaching anybody anything so I wouldn't apply a haughty phrase, as it were, but certainly / see reaching out and finding new people, more to the point actually reaching out to existing jazz fans who, like me, just didn't know what was there live, and telling them that this is something that is important. It's here and it's contributing to the world output of jazz in a very, very meaningful way and if you like that music and you get pleasure from it, you have a duty to support that in some sort of way, morally.

The imperative to bring the music and its broader philosophy to the attention of new audiences and new generations of listeners, and to 
counterbalance perceived lack of attention by cultural commentators of the mainstream, provided a common theme:

Promoter E: I do see myself as carrying the flame. Jazz is such a marginalized music, somebody has got to bring the next generation through ... [...] It's enlightened self interest, I want to live in a world where jazz is valued and because our music is marginalized by the media and by all those people who control things. Because they won't invite us to their party we have to invite other people to ours, you know. [...] I want to sell a philosophy that jazz is great and all these other people can be part of it as well. [...] ... because jazz is evidently the most important music on the Planet. We all know that but we have to prove it, and the way I prove it is by having that platform by showing jazz in the context itself and in the context of other musics and showing what we can do.

In addition to expressing feelings of obligation to the furthering of jazz and the development of new audiences, some interviewees saw themselves 
as gatekeepers, as curators and enablers, and even as co-instigators of the creative act:

Promoter A1: You've got to think that we're, you know, 'editors' and 'publishers'. So, you know, there's a lot of material out there. What do we want in our edition? What are our audience looking for? What are they going to buy?

Such proactive activity also included the nurturing of young, or as yet inexperienced, talent:

Promoter C: But I also challenged local ... I went to [musician's name] ... and said: "Look, you've got a gig in three months time in [city A] and [city B], I want a programme of two hours all original music, go!" "Oh... who can / use?" "You choose."

Promoter D: ... whilst we are very open to people who perhaps aren't as capable, they get the opportunity here, but in return they are loyal to us, so that's good. [...] ... there are at least two or three examples of 
individuals who came in here, could hardly get through a song, cut their teeth and are now gigging.

The process of nurturing emerging talent was also seen to be perceived as beneficial to the aspirations of the individual promoter:

Promoter E: ... for example / played with a young chap called [musician's name] who's like a teenager, I actually saw him in [another venue], great player, so I got him to play. That's typical of how I see people that I like and think: "Wouldn't it be great if they played?" And also here's a chance to expose this young impressionable person to maybe a different way of playing jazz than they're used to, because they get taught certain things in college and the kind of collective improv I do, the kind of free-form fusion thing I do ... I can kind of sell this to these young players, and, you know, promote my music as well... well my musical philosophy as much as the jazz thing generally.

As noted earlier, jazz promoters are often connected to the music through being, or having been, musicians themselves. Where such a direct 
connection might be viewed in the terms of 'a conflict of interests', it nonetheless affords a degree of shared understanding with the musicians that they present. Conversely, where promoters do not themselves play an instrument, their relationship could be described as being more closely aligned with the audience. Regardless, it becomes clear through the analysis of interview data that the promoters' sense of duty to the health of jazz, its audience and its scene, form a common aspect in terms of their self-identity. In the fulfillment of this duty, the promoter seeks to grow the audience for jazz, raise knowledge and awareness of the music and its heritage, and provide support for established and emerging musicians through putting on gigs. These activities are often perceived as running against the grain of mainstream media and culture, forces that are typically seen as obstructive.

Artists, audiences and communities 
The place of the promoter within the social fabric of the local jazz scene emerged as important to the self-identity of the interviewees. A sense of shared values with the musicians and audiences was expressed:

Promoter A: The communality of it, the friendship, the fun, the humour, you know, all of that. I think it creates a kind of family sense ... [...] And the other thing that I think is really important to mention about jazz, is that it's the most social music, so ... any musician can go anywhere in the world and immediately find a bond with a fellow jazz musician. And, equally, jazz audiences can fit into that family. There is a family feel to jazz that doesn't exist in pop and rock music. [...] And, so, why do you promote jazz? Because you also like jazz musicians. I mean, despite the fact that they can be 'tricksy' ... and despite all the other issues, you like jazz musicians.

In foregrounding the commonalities amongst those within the jazz community (while hinting at frictions), the need to keep abreast of change was acknowledged: 
Promoter C: Knowledge of the scene, I try and stay as knowledgeable as possible [...] ... it's important to meet people on the scene and invariably names come and it's like "oh, who's this, new guy on the scene, I will check him out".

As well as to provide a nurturing environment for musicians:

Promoter D: ... we wanted the audience here, we wanted the musicians here meeting because it was where 'everyone went' on a Sunday night and you'd know that you would bump in to your pals. It's somewhere that over a pint, you know, perhaps you would have a little play in the jam or if you were listening to a particular host artist you would have a backdrop that you could, you know ... that you knew was there every week and that you could then use to provide you with an opportunity to get together and to potentially ... We always hoped that this would be the place that ideas would be seeded.

The desire to provide creative incubation spaces was not necessarily confined to the inclusion of musicians from the jazz discipline: 
Promoter E: I'm really keen about bringing other musicians in to our space and also musicians from other disciplines, because what we do is we have musicians from the classical world, the folk work, we have poets, we have dancers. So I am trying to open a space up where jazz is the main thing but other musicians and other cultures are coming in to that space and we can share it, you know, so I am trying to open things up and create a kind of umbrella thing.

An appetite for inclusivity was thereby indicated by those interviewed, both in terms of providing a space for those within the scene, and in inviting those from beyond its perceived borders of genre and discipline. There are obvious tensions present in the spirit of inclusivity alluded to, however, in that programming decisions ultimately rest with the promoter, meaning that not all musicians are necessarily created equal in the promoter's selection of who gets to play.

\section{Programming decisions}


A variety of factors govern the programming decisions of promoters interviewed. The issue of building an audience from the basis of known quantities and encouraging wider participation in events was raised:

Promoter B: You have people that already know the artist, so they're your soft target and you want them to know about it and they are normally the easier ones to communicate with. Then you have a bunch people that might be curious, so they're kind of next down on the list, they might be curious or not entirely convinced but might go if a friend is going or if something changes in their perception of the artist, so your trying to say: "listen to this artist again, they are good aren't they? You should buy tickets to come to the show." So you are trying to persuade them into saying this is going to be a good experience and worth them investing in. Then you have the near impossible people ... to get through to, [who are] not paying attention to any cultural outlets whatsoever, not aware of who the artist is, so you're going to have a really hard time persuading them to come to the show. So you always 
concentrate on the easiest target first and then you expand in to the harder and harder groups ...

The understanding of the market place specific to a venue was also highlighted. Matching a venue's offering in terms of genre and style with the expectations of specific audience demographics played a key part in programming decisions, although cross-fertilization between distinct audiences was seen a positive aspect of multi-genre programming. Promoter C: I program according to what I think is going to go down in this particular environment on certain nights of the week. [...] ... of music we put on in the [venue], one third is jazz, one third is kind of roots, blues, acoustic singer/songwriter kind of stuff and the other third is funk/soul electric which is mostly the late night. Each of those one-third sectors brings in a different audience and there are crossovers all over the place. [...] The common denominator is it's all good quality music, so if someone comes in for an acoustic gig that finishes at 8:30, they're 
like: "What's on next? Jazz? I don't like jazz, oh I'll stay for another pint ...

God these guys are good, who's that trumpet player?"

Inter-scene tensions became apparent when promoters expressed

frustration at musicians' reticence in engaging with live music as audience

members:

Promoter C: One thing that constantly disappoints me is the musicians.

They don't come to the gigs. For God's sake get in there! There is so

much good stuff happening, especially on the [funded promotion] side

of things, which is stuff you can't hear anywhere else. There's not

enough actual musicians coming out, on a Wednesday night, Thursday

night. I don't believe they are all working, but there should be a lot

more interest in that.

Further frictions were highlighted in the discussion of perceived inequalities and lack of structure amongst promoters themselves:

Promoter E: I don't talk to those other people [jazz promoters], I don't share ideas with them, I've never been invited to share ideas with them. 
There seems to be no real structure, no overall structure provided by anybody, especially once you are funded which I suppose / ought to be, networking ... which is strange because [the scene under discussion] is a very small place, you would think that we would get together but we don't. So I am very much operating in a slight vacuum in a way. Having said that, you know, almost all of the musicians I play with play in these other places as well, most of them, apart from the ones who aren't jazz players. So we are connected maybe socially but not musically, in a weird kind of way.

In summarizing interview data on programming, it becomes apparent that audience development is central to decision making. Whether through multi-genre programming in order to encourage cross-fertilization between fans of different musics, or promoting word-of-mouth hype around an artist, attracting an audience is, unsurprisingly, the primary objective amongst the majority of promoters. The activities of the various promoters interviewed, and by extension perhaps typical throughout the wider jazz scene, do not appear however to be particularly interconnected, with each 
adopting a point of difference, or degree of exclusivity, in their operations.

It is interesting to note that the only section of the potential concert

audience that was subject to direct criticism by those interviewed was

musicians themselves. This suggests that promoters feel to some extent

aggrieved that their efforts in presenting new music, with the intention of invigorating and developing the scene, go unappreciated by those that on another day they might also promote. A sense of alienation experienced by one promoter (also a musician) was expressed, indicating that those who steward the presentation of live jazz on the local scene are not necessarily of a single mind when it comes to who and what to present, and how and where to present it - again in spite of the shared values alluded to earlier in this article.

\section{Economies}

The economies in which each of the interviewees operates varied widely,

from government and local authority funded festivals, to ticketed and nonticketed (i.e. free) events, and reliance on bar sales and/or corporate 
sponsorship and goodwill, for example. Sponsorship of the arts was broadly agreed to be necessary to the financial and cultural health of the jazz scene, either generally or in specific instances. The difficulties in attracting corporate sponsorship in the promotion of jazz were alluded to: Promoter A: Well let's put it this way, if there was no public funding for jazz musicians, of any type, the musicians wouldn't be there for those [promoters] to be able to book. Because, all of those musicians are, in one way or another, earning a part of their living out of a public funded economy. [...]

The same interviewee pointed to increased difficulties in attracting corporate sponsorship, rather than placing responsibility solely with local or central government funding strategies:

Promoter A: I don't think there's been a shift, though [from corporate to public sponsorship], you know, there's been public funding in jazz for 40 years, you know. So I don't think I don't think there's been a shift from one to another. What I think is that there's much less value in corporate 
sponsorship of live music for the reasons that we've already discussed,

which are that there's much less media attention. So, it's much more

difficult for us to give a corporate sponsor the kind of financial benefits

that we could give them 10/15 years ago.

The role of public sponsorship could nonetheless be observed, in

interviewees reporting that some projects were only made possible

through the underwriting of public funding bodies:

Promoter B: I can see why it [public funding] is useful, I can see why

there are certain projects that couldn't be done commercially. The

[venue] just did the [band name] orchestral thing, which I went to, and

that wouldn't have worked financially. There was over 30 people in the

touring party and there's not a chance / would have even considered

putting that on, if that group were not subsidized and I wasn't being

subsidized for doing it [...] So those kind of projects really do work in a

subsidized venue. [...] 
But for this interviewee, a 'capitalist' model was at the core of the majority of promotional activities, albeit somewhat at odds with political beliefs typically shared with others in the music industries:

Promoter B: We do something like 200 shows a year at [named music promotion company]. Every one of those shows is like a new capitalist project that you're investing in and you hope to see a return on. So there is kind of that entrepreneurial thing going and I would say most the people in the music industry were left-leaning, so you've got this odd contradiction at the heart of it that we are all quite liberal or "lefty" and ... [pauses] ... rampant capitalists.

One promoter identified a reliance on mixed income of ticket and bar sales. Specifically, the bar revenue sustained the running of the venue, and ticket revenue supported musicians on the venue's programme: Promoter C: Its [the venue's] only income is bar sales. Every gig that is put on in the [venue] has a door charge but that money all goes to 
musicians who are playing on that particular time slot, none of it goes

to the venue.

The same promoter conceded, however, that lines were often blurred between bar and musician income:

Promoter C: On the late night gigs, we will top up the money. If it's absolutely minimal, we will top it up with some bar money, and we do that on most late night gigs - the 12:00 - 3:00 slot, 7 nights a week, the bands are getting a bar percentage as well as the door money, which is a reasonable rate for a Sunday night at 2am or a Monday night or Tuesday night at 2am [...]. So these guys are getting ... we are contributing a lot of money to the [local] music economy on both those fronts.

The difficulties in achieving a financial return through presenting nonticketed (free) music to a venue's customers was observed by one interviewee: 
Promoter D: ... the important thing is that it doesn't pay. It doesn't pay a venue to do it unless you can ticket it. [...] In fact for it not to cost them a lot of money, and even when you have musicians paid modestly, as is the case here, and you have a good regular audience, and the place is buzzing and kicking, the venue's income from doing it is minuscule. It wouldn't, generally speaking, cover their wages bill for the night, so it's really very, very difficult to make the economics work. [...]

To further make the point about the lack of financial return to the host venue for unticketed gigs, Promoter D provided this example:

Promoter D: Broadly speaking, if you take a common bar model - lets suppose you were going to employ five people [musicians] at a hundred quid - I'm not giving you a direct example of the financials here, but supposing that was you know, broadly speaking, what people regard to be an MU rate, to pay five musicians a hundred quid. So a five hundred quid bill, in the till in a bar or a bar/restaurant like this, everything that goes in has VAT on it, so you knock $20 \%$ off and if you modestly say 
everything is costing half what your selling it for, the simple maths is that you have to take twelve hundred quid into a till to simply cover that five hundred pounds - three of four hundred pints of beer. It doesn't take much to figure out what the reality is of that when you look at a venue like this on a Sunday night with people not looking to buy three or four hundred pints of beer, wanting [instead] to have a cup of tea and a glass of water ... so the mechanics of it are very, very difficult to achieve.

Despite the difficulties in making music pay in the short term, Promoter D maintained that there were nonetheless potential benefits to the venue: Promoter D: The income from the music on a Sunday night equates to probably something like fifty to seventy percent of what the musicians are physically paid, so they ain't getting rich on this and it hasn't paid the rent, the rates and their staff bill. But it's turnover, and turnover adds value to the business if you were going to sell the business, so to a corporate financier it has a value. 
In relation to public funding, the same interviewee implied that it could be seen as a 'financial bailout' of the 'jazz economy', chiming with Brennan and Webster's assertion that much of the financial risk in concert promotion is "distributed and borne, in part, by the public sector." (2011: 17):

Promoter D: I found myself in a jazz forum once talking about the jazz economy, and everyone steamed up about bank bailouts and sitting there listening to comments people made around the table and talking about the jazz economy, a subject so close to my heart, I couldn't help but think: "What economy?" [...] ... and the lack of people spending money on it [jazz], means that it exists in a state of permanent bailout and that permanent bailout is [the national arts funding body].

In the absence of public funding or corporate sponsorship, the desire to keep ticket prices competitive and affordable in order to attract an audience were seen to have direct, and typically negative, consequence to the earnings of musicians. 
Promoter E: We charge five pounds, three pounds for students. So admissions, given we have three bands on every gig, five pounds for three bands, I think is pretty good value. [...] Yes, the musicians come knowing that they are going to get very little money. They might get their travel expenses if they are lucky, depending on how many people come, so it is clear that the money isn't the reason for doing it. It really is music-centric.

Promoter $\mathrm{E}$ is careful to point out that, despite meager wages available to the musicians promoted, nobody within their specific chain of production was making any significant financial returns from their activities:

Promoter E: I am not exploiting people. I'm not making money from it. In fact I lose money every gig. I lose at least twenty quid every gig because I am paying people out of my pocket. So it's an investment in the music. I don't really have any serious hope about it being a viable proposition money-wise. 
Through the analysis of interview data, a picture emerges of a complex and fractured economy that relies variously on public funding, ticket sales, commercial sponsorship, and the goodwill of promoters and musicians. For some, activities are only practicable through the receipt of external funding and/or ticket sales. Other are subject to interdependencies with the venue at which promotions take place. And others still, promote music in which they believe at any cost (or in the absence of any financial return).

\section{DISCUSSION:}

Those interviewed for this study clearly exhibit a range of attitudes and approaches to jazz promotion, and motivations for becoming involved in this area of activity. A number of 'types' of promoter emerged from the data, and these can be categorised as follows: the dedicated professional, for whom the promotion of jazz represents full-time employment; the occasional, for whom jazz is an adjunct to a broader promotion portfolio; the amateur, who supplements their income through ad hoc promotion of 
jazz, and the altruistic hobbyist, for whom profitability is not a motivating factor.

Where it might be expedient to discuss motivations within the delineations of these characterisations, it became clear that there were considerable overlaps between them. Only one interviewee claimed to care little about financial remuneration for their efforts and those of the musicians they presented, focusing instead on the cultural capital in providing a creative space for collaboration and experimentation. The remaining promoters interviewed trod a rather more complex path between promoting the music that they deemed important while attempting to ensure the financial viability of their activities. This balance was achieved either by promoting jazz as an addition to their core offering, by seeking external subsidy, or relying on the goodwill of venues and musicians. In examining the types of jazz promoted by the interviewees, it is (perhaps unsurprisingly) typical that more progressive, experimental jazz is presented where financial viability or gain is not the primary instigator and, conversely, that more 
established forms are promoted by those of with more commercially

framed outlook.

As supported by Riley and Laing's 2006 study, The Value of Jazz in Britain (updated 2008) the majority of promoted live jazz continues to take place within a framework that encompasses residencies in local clubs and pubs, one-off events in civic halls and private or corporately owned venues, and in multi-performance festivals. All of these environments are governed, to varying degrees and in different ways, by the need to attract revenue through ticket sales or through partial commercial or public subsidy. The sustainability of activity of those working within a wholly commercial setting, that is to say without financial input from the public purse, is subject to ticket-income (if applicable) or third-party benefits (bar takings, an increased footfall to the host venue), or combinations thereof. One promoter, was clear in the assertion that un-ticketed live music does not provide significant, if any, direct financial income to a venue on the outlay of paying for musicians. Instead, any financial return is achieved by live music serving to add 'value' to the venue through increased footfall, 
diversification of clientele, or in establishing an identity beyond simply its location and furnishings, for example. Another promoter similarly decried the notion that bar-takings alone had the potential to pay the bill for live music, offering instead a model that combined ticket income with top-up from bar-sales as and when required. The same promoter, however, conceded that this model was not practicable for bigger name or international musicians or bands whose expectations in terms of pay and subsistence are higher than those on the local scene, and pointed to the need for subsidy in order to make such gigs happen at all. These heightened expectations of remunerations are typically tied to the costs involved in touring (travel, accommodation, subsistence, loss of other earnings) rather than necessarily any perceptions of greater value to an audience.

The festival promoter interviewed went as far as to say that their activities would be impossible without public funding. With the diminishing of corporate sponsorship, for reasons pointed to earlier in the article, coupled with waning press interest in the genre (Riley and Laing 2008), some 
international jazz festivals have become simply unviable without funding from central and/or local government, or significant corporate sponsorship. The argument for such investment can undoubtedly be made for the cultural capital fostered through the support for preservation of heritage and creative innovation, and third party benefits from tourism. However, the frictions between promoters (and thereby musicians and other actors in this network) who benefit from the support of public finances, and those who do not were evident in the interviews conducted with one respondent likening arts council subsidy to 'bailout'. Anecdotally, the authors are aware of a degree of 'sour grapes' voiced amongst some musicians on the local scene who subscribe to widely held perceptions that subsidy favours the international over the local in programming decisions. It must also be conceded that the international aspect provides a bigger audience draw through its exclusivity and 'exoticism'. Local musicians, after all, can often be heard locally at any time - and often for a more modest ticket price or, indeed, for free. 
Through examining the various platforms on which live jazz is presented in the city in which this research took place and the underpinning economic models that govern them, it is clear that the promotion and performance of jazz can therefore not be easily conflated into a single understanding. Rather, the associated activities should be viewed through a variety of lenses. From the promoter's perspective: impetus and economic model; and from the musician's perspective: stylistic offering, and potential audience draw. Taken together, the operations (governed as they are in part by external factors of economics and public zeitgeist) of local promoters have a significant impact on the shaping of the scene. This study provides a snapshot of activity at a time in which jazz has become firmly established in the higher education curriculum and increasingly professionalised. There are increasing numbers of highly trained musicians vying for shrinking opportunities in which to ply their craft and earn a living. This coincides with a downturn in public appetite for jazz, certainly when compared to its heyday in the first half of the $20^{\text {th }}$ century and its brief revival in the 1980s. The jazz audience demographic is 
aging (Lawes et al. 2016: 13) and the challenge during financially straitened times is to rebuild a younger audience in order to survive the future. Since the 1970s (and traditionalists would argue even earlier), jazz has become increasingly difficult to define within the terms of genre, having borrowed from and added to surrounding high and lowbrow culture. Non-jazz audiences, unsurprisingly, tend to readily identify jazz from earlier eras those in which jazz had a more definable identity. Promoters, and in particular festival promoters, are thereby put in the challenging position of presenting what the audience perceives as authentically jazz while providing a stage for emerging, acculturated, or less familiar stylistic branches of the genre. At the same time, promoters tread a tightrope between satisfying the demands and expectations of an aging audience while trying to lure younger concertgoers through repackaging classic repertoire or presenting content of more perceived youth relevance. Herein lies a tension that should be approached with caution for the health of both the local and global jazz scene. In the promoters' selfidentified roles as curator and gatekeeper, for example, decisions around 
programming and presentation do not necessarily chime with value structures associated with the playing of jazz as perceived by musicians and, indeed, some sections of their audience. Festival programmers frequently face accusations of being 'safe' or unimaginative in their programming of higher grossing, 'big' acts (often not considered authentically 'jazz') in favour of higher risk, progressive alternatives. Most musicians in the authors' circle of experience view authenticity (whether in terms of artistic intent or technical prowess) as the litmus test for what 'ought' to be presented to audiences, feeling aggrieved that promoters often appear ignorant or turn a 'deaf ear' to these perceived qualities. In the promoter's pursuit of making 'financial sense' in presenting a music of specialised audience, their decisions are often seen as reactionary, and the power they wield as gatekeepers as counterproductive to the development of both the genre's musical language and its audience.

Where the reasons given by the interviewees for promoting jazz could overwhelmingly be interpreted as 'wholesome' and laudable, the economic and cultural ecologies into which their activities fit cause frictions between 
their own motives and those of the musicians they present (or consider themselves unable to present). Further work on building bridges of understanding between creators and promoters in jazz, and their supporting industries, is therefore central to fostering mutual understanding towards combined strategies. Promoters and musicians are inextricably co-dependent players within the same industry and contributors to the same scene. Indeed, promoters themselves appear somewhat disconnected from one another within their metier even in spite of the 2016 establishment of the UK-wide Jazz Promoters Network. Therefore, a deeper multilateral understanding with input from academia, creative practice and industry would undoubtedly provide nourishment for the health and longevity of the music and those that are involved in its performance, industries and reception.

\section{BIBLIOGRAPHY:}


Behr, Adam, Emma Webster, and Matt Brennan. 2015. Edinburgh Live

Music Census 2015 - Pilot Study. The University of Edinburgh, Live Music

Exchange. [Online]. Available at: http://livemusicexchange.org/wp-

content/uploads/Edinburgh-Live-Music-Census-Report.pdf (accessed

03/12/16).

Brennan, Matt and Emma Webster. 2011. Why Concert Promoters Matter.

Scottish Music Review Vol.2, No. 1.

Burland, Karen and Stephanie E. Pitts. 2010. Understanding Jazz Audiences:

Listening and Learning at the Edinburgh Jazz and Blues Festival. Journal of

New Music Research. Vol. 39, No. 2, pp. 125-134. Routledge.

EKOS. (2013, rev. 2014). Music Sector Review - Final Report for Creative

Scotland. Produced in collaboration with Judith Ackrill Associates \& Nod

Knowles Productions. [Online]. Available at:

http://www.creativescotland.com/_data/assets/pdf_file/0014/21470/Creativ

e-Scotland-Music-Sector-Review-v1-2.pdf (accessed 16/09/16). 
Frith, S. 2010. Analysing live music in the UK: Findings one year into a three-year research project. IASPM Journal. Vol. 1. No. 1.

Frith, S. 2012. Editorial. Social Semiotics. Vol. 22. No. 5. pp. 517 - 522.

Lawes, H et al. (2016) The Needs of the Jazz Community. Report

commissioned by Jazz Services. [Online]. Available at:

http://jazzuk.org.uk/wp-content/uploads/2016/09/Final-Report-Jazz-Needs-

16th-September-2016.pdf (accessed 15/10/16).

Leonard, N. 1986. The Jazzman's Verbal Usage. Black American Literature

Forum Vol. 20, No. 1/2. pp. 151-160. African American Review. St. Louis

University.

McRae, R. 2001 "What Is Hip?" And Other Inquiries In Jazz Slang

Lexicography. Notes, the Quarterly Journal of the Music Library Association.

Vol. 57 , No. 3, pp. 574-584

Medbøe, Haftor and José Dias. 2014. First Monday. University of Illinois at

Chicago University Library. 
Montoro-Pons, Juan D and Manuel Cuadrado-García, M. 2011. Live and prerecorded popular music consumption. Journal of Cultural Economics. Vol 35. Issue 1. pp. 19 - 48. Springer Science+Business Media. Berlin.

Pinheiro, R. F. 2014. The Jam Session and Jazz Studies. International Review of the Aesthetics and Sociology of Music Vol. 45, No. 2. pp. 335-344. Croatian Musicological Society.

Riley, Mykaell and Dave Laing. 2010. The Value of Jazz in Britain I/. Report commissioned by Jazz Services Ltd. [Online]. Available at: http://www.chrishodgkins.co.uk/wp-content/uploads/2015/01/Value-OfJazz-in-Britain-2-2008.pdf (accessed 04/10/16).

Riley, Mykaell and Dave Laing. 2008. The Value of Jazz in Britain. Special Report - Jazz in the Media. Report commissioned by Jazz Services Ltd.

[Online] Available at: http://www.chrishodgkins.co.uk/wpcontent/uploads/2015/01/Jazz-Services-Media-Report.pdf (accessed 04/10/16). 
Wall, Tim and Simon Barber. 2015. Collective Cultures and Live Jazz in

Birmingham. In The Cultural Politics of Jazz Collectives, eds Nicholas

Gebardt and Tony Whyton, 137 - 131. New York: Routledge

Leonard, N. 1986. The Jazzman's Verbal Usage. Black American Literature

Forum Vol. 20, No. 1/2. pp. 151-160. African American Review. St. Louis

University.

McRae, R. 2001 "What Is Hip?" And Other Inquiries In Jazz Slang

Lexicography. Notes, the Quarterly Journal of the Music Library Association.

Vol. 57, No. 3, pp. 574-584 